\title{
PERBEDAAN POLA RUGAE PALATAL ANTARA LAKI-LAKI DAN PEREMPUAN SUKU MINANG
}

\author{
Dhira Pratiwi ${ }^{1}$, Dedi Sumantri ${ }^{2}$, Nur Indrawati Lipoeto ${ }^{3}$ \\ ${ }^{1}$ Fakultas Kedokteran Gigi Universitas Andalas, Padang, Sumatera Barat, Indonesia \\ ${ }^{2}$ Fakultas Kedokteran Gigi, Universitas Andalas, Padang, Sumatera Barat, Indonesia \\ ${ }^{3}$ Fakultas Kedokteran Universitas Andalas Padang, Sumatera Barat, Indonesia
}

\begin{abstract}
Indonesia as a disaster-prone area allowed casualty in large numbers and need immediate identification. One way to identify it was the use forensic odontology. Palatal rugae pattern has been suggested as an alternative method in forensic odontology to determine gender in all sorts of ethnic and population. The aim of this study was to know the difference of palatal rugae pattern between males and females in Minang ethnic. This study used descriptive analytics with cross sectional approach. The study sample compromised 122 dental stone casts of Minang ethnic, 61 males and 61 females wih range 15-19 years. The method rugae identification was based classification of Thomas and Kotze. The data were analyzed by Mann-Whitney test. The most predominant palatal rugae pattern in Minang ethnic are wavy and primary rugae. The Minang males were predominantly wavy, followed by straight, curve, unification, and circular. The Minang females were predominantly wavy, followed by curve, straight, and unification. There was a significant $(p<0,05)$ sex difference in the circular type which was higher in males. Palatal rugae pattern can be used as adjunct to sex differentiation between males and females of ethnic Minang in forensic odontology.
\end{abstract}

Key words : Forensic odontology, analysis of rugae palatal, gender, Minang ethnic

Affiliasi penulis: ${ }^{1}$ Faculty of Dentistry Andalas University

Korespondensi: Dhira Pratiwi email:

\section{PENDAHULUAN}

Indonesia merupakan salah satu kawasan rawan bencana di dunia. Kondisi ini disebabkan oleh keadaan geografis dan demografisnya. Kondisi ini meningkatkan resiko korban meninggal dalam jumlah besar dan membutuhkan identifikasi segera. Salah satu cara untuk mengidentifikasinya adalah penggunaan ilmu odontologi forensik. Odontologi Forensik atau Kedokteran Gigi Forensik merupakan cabang ilmu kedokteran gigi yang berperan dalam proses peradilan untuk pembuktian kasus kejahatan tertentu dan sebagai sarana identifikasi terhadap korban meninggal yang tidak dapat dikenali Odontologi Forensik memiliki banyak metode yang bisa digunakan antara lain penggunaan cetakan gigi, radiografi, fotografi, rugoscopy, cheiloscopy. ${ }^{1,2}$

Ahli Odontologi Forensik menggunakan gigi sebagai salah satu sarana yang paling sering digunakan dalam melakukan identifikasi, karena dapat dipercaya, akurat, dan bisa diandalkan ${ }^{3}$. Gigi tidak bisa diandalkan dalam proses identifikasi pada beberapa kasus tertentu, misalnya pada korban dengan gigi yang 
mengalami avulsi akibat trauma, kondisi rahang edentulous. Korban dengan kondisi edentulous, fotografi dan radiografi tidak bisa digunakan lagi ${ }^{4}$

Gigi memiliki keterbatasan pada kasus tertentu dalam Odontologi Forensik, sehingga dibutuhkan alternatif lain. Alternatif itu adalah rugoscopy atau analisis pola rugae palatal. Rugea palatal merupakan sarana alternatif yang ideal dalam melakukan identifikasi forensik pada kasus tertentu karena simpel dan akurat ${ }^{5,6}$.

Rugae palatal memiliki tingkat individualistik yang tinggi pada tiap rahang, bahkan pada anak kembar tidak ditemukan pola rugae yang identik sehingga keakuratannya bisa disejajarkan dengan sidik jari ${ }^{2,5}$. Rugae bisa digunakan sebagai alat identifikasi personal pada korban. Rugae berada didalam rongga mulut sehingga terlindung dari trauma dan suhu yang tinggi pada daerah maksilofasial ${ }^{5}$.Rugae juga bisa bertahan dalam pola normal lebih dari 7 hari setelah kematian tanpa mengalami dekomposisi ${ }^{7}$. Pola rugae dapat berubah akibat trauma, namun akan tetap stabil seumur hidup walaupun rahang mengalami pertambahan ukuran pada masa pertumbuhan, ekstraksi gigi, rahang edentulous, perawatan ortodonti, dan setelah penggunaan protesa ${ }^{2}$.

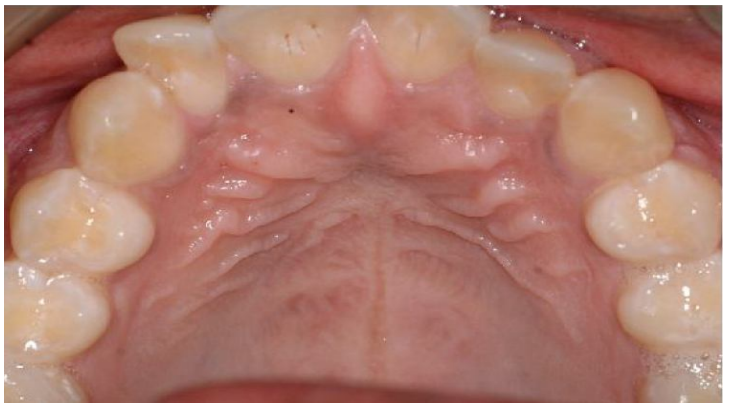

Gambar 1 Rugae Palatal ${ }^{5}$

Pola rugae palatal juga bisa digunakan untuk mengidentifikasi individu, gender dan ras. Beberapa penelitian menunjukkan bahwa rugae palatal memiliki karakteristik pola pada populasi dan gender tertentu. Karakteristik tersebut menjadikan pola rugae palatal sebagai salah satu sarana identifikasi forensik untuk menganalisa individu, gender maupun ras.

Pola rugae palatal sangat diperlukan dalam proses identifikasi forensik. Penelitian yang telah di uraikan diatas menyebutkan bahwa terdapat perbedaan jumlah dan jenis pola antara laki-laki dan perempuan pada satu suku bangsa. Pola rugae palatal sangat bervariasi pada tiap suku bangsa didunia, termasuk suku Minang di Indonesia. Suku Minang merupakan populasi suku terbesar di Sumatera Barat yang termasuk bagian dari sub ras Deutro Melayu ${ }^{8}$. Sejauh yang peneliti ketahui, belum ada penelitian mengenai pola rugae palatal pada suku Minang di Sumatera Barat. Peneliti tertarik untuk melakukan penelitian mengenai 
perbedaan pola rugae palatal antara lakilaki dan perempuan suku Minang.

Rugae palatal memiliki peran dalam bidang genetik, sistem stogmatognatik, prostodonti, ortodonti dan odontologi forensik ${ }^{9}$. Rugae memenuhi 5 syarat sebagai salah satu alat dalam identifkasi forensik ${ }^{10}$

1. Individual

Memiliki karakteristik yang berbeda tiap individu. Pola rugae palatal memiliki bentuk yang spesifik antar individu seperti sidik jari. Tidak ada kesamaan morfologi rugae pada orang yang berbeda, termasuk pada kembar identik ${ }^{3}$

\section{Immutability}

Tetap bertahan dalam bentuk yang sama seumur hidup. Peavy dan Kendrick menyatakan bahwa karakteristik pola rugae tidak berubah karena pertumbuhan dan stabil hingga degenerasi mukosa oral saat meninggal. Bentuk pola rugae dapat stabil seumur hidup ${ }^{11}$. Mutthusubramanian menyatakan bahwa pola rugae palatal pada $93 \%$ cadaver dengan luka bakar derajat tiga pada wajah tidak mengalami perubahan bahkan setelah tujuh hari kematian. Proses menua dan ekspansi palatal tidak menyebabkan perubahan signifikan pada pola rugae ${ }^{4}$.

\section{Perrenity}

Memiliki kemampuan untuk bertahan terhadap berbagai tindakan. Rugae palatal terletak pada tempat yang strategis didalam maksila, dilindungi oleh struktur kepala, lidah, bucal pad. Rugae berada didalam pipi sehingga terlindungi dari perubahan suhu pada bagian maksilofasial. Gusi dan alveolar ridges mencegah terjadi kerusakan pada postmortem. Rugae jarang mengalami kerusakan akibat trauma, luka kimia, dan perubahan suhu ${ }^{3}$. rugae palatal ketiga tidak mengalami perubahan bentuk antara sebelum dan sesudah operasi celah palatum ${ }^{4}$. Rugae merupakan jaringan lunak yang paling terlindung dari trauma, suhu, mekanik karena terletak antara dasar kavitas nasal superior, lidah, bibir, dan insisivus anterior maksila, pipi, serta molar maksila. Rugae palatal dapat bertahan dari efek suhu dan dekomposisi akibat luka bakar derajat tiga dan tempat penyimpanan mayat $^{12,13}$.

\section{Practicability}

Mudah diaplikasikan, biaya yang tidak mahal, mudah dicatat atau direkam.

\section{Possibility of classification}

Hasil identifikasi harus bisa dicatat dalam bentuk file dan memiliki klasifikasi yang jelas. Rugae memiliki banyak klasifikasi.

Thomas dan Kotze mengklasifikasikan pola rugae secara kompleks berdasarkan ukuran, bentuk, arah dan unifikasi. Rugae palatal dibagi menjadi rugae primer jika panjangnya lebih dari 5 $\mathrm{mm}$, rugae sekunder jika panjangnya antara 
3-5 $\mathrm{mm}$, dan fragmenter jika panjangnya kecil dari $3 \mathrm{~mm}$. Rugae palatal juga dikelompokan menjadi empat tipe berdasarkan bentuknya yaitu, kurva (curved), bergelombang (wavy), lurus (straight), sirkular (circular). Pengelompokan rugae berdasarkan bentuk unifikasinya yaitu konvergen jika dua rugae dengan asal yang berbeda, kemudian menyatu pada bagian tengah. Pola divergen jika rugae dengan asal yang sama, bercabang pada bagian tengah. Bentuk rugae dikatakan unifikasi jika terjadi penyatuan dua buah rugae baik pada pangkal atau ujungnya ${ }^{14}$.

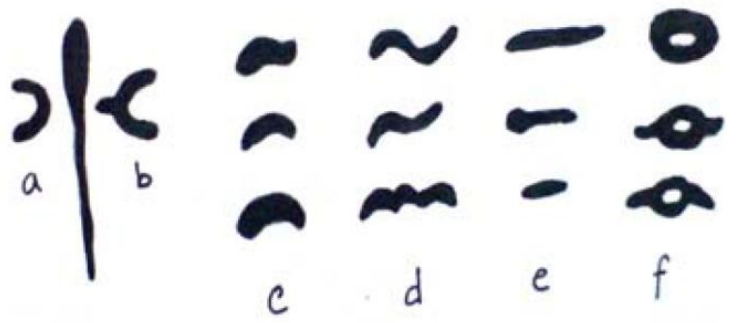

Gambar 2.3 Klasifikasi Thomas dan Kotze a.b unifikasi c. Kurva d. Bergelombang e. Lurus f. Sirkular ${ }^{4}$

\section{METODE PENELITIAN}

Penelitian ini merupakan penelitian observasional dengan pendekatan potong lintang atau cross sectional study, karena penelitian ini dilakukan sesaat tanpa tambahan followup penelitian. Penelitian ini dilakukan diruang laboratorium Biologi dan area SMKN 3 Kota Pariaman. Penelitian ini dilaksanakan pada tanggal 18 Februari 2016 sampai tanggal 8 Maret 2016. Jumlah sampel yang diperlukan adalah sebanyak 61 orang laki-laki dan 61 orang perempuan. kriteria inklusi sampel adalah sebagai berikut :

a. Usia minimal 15 tahun

b. Suku minang ( 2 keturunan minang)

c. Menandatangani informed consent

d. Tidak sedang menggunakan gigi tiruan penuh atau gigi tiruan sebagian lepasan pada rahang atas

e. Tidak atau telah melakukan perawatan ortodonti cekat rahang atas

f. Belum pernah dilakukan ekstraksi pada gigi anterior atau gigi premolar rahang atas

g. Tidak memiliki kebiasaan buruk seperti menghisap ibu jari

h. Tidak sedang mengalami inflamasi pada rongga mulut

\section{Kriteria Eksklusi}

Adapun kriteria eksklusi sampel adalah sebagai berikut

a. maloklusi berat pada rahang atas

b. penderita celah palatum

c. pernah dilakukan operasi pada bagian palatum

d. pernah mengalami trauma berat pada palatum

e. refleks muntah tinggi

f. memiliki torus palatal yang mengganggu pencetakan rugae palatal 
HASIL PENELITIAN

\begin{tabular}{|c|c|c|c|c|c|}
\hline Ukuran & Gender & $\mathrm{n}$ & $\begin{array}{c}\text { Median } \\
\text { (min- } \\
\text { maks) }\end{array}$ & Mean \pm SD & $\boldsymbol{p}$ atas. Perbedaan yang signifikan $(p<0,05)$ \\
\hline \multirow{2}{*}{$\begin{array}{l}\text { Rugae } \\
\text { Primer }\end{array}$} & L & 61 & $9,0(5-14)$ & & \multirow{2}{*}{$\begin{array}{l}\text { hanya pada rugae dengan bentuk sirkular. } \\
0,299 \\
\text { Pada pola lain tidak ditemukan perbedaan }\end{array}$} \\
\hline & $P$ & 61 & $8,0(3-13)$ & $8,15 \pm 2,143$ & \\
\hline \multirow{2}{*}{$\begin{array}{l}\text { Rugae } \\
\text { Sekunder }\end{array}$} & L & 61 & $2,0(0-5)$ & $2,08 \pm 1,115$ & \multirow{4}{*}{$\begin{array}{c}\text { 0,379yang signifikan antara bentuk rugae laki- } \\
\text { laki dan perempuan. Perbedaan yang } \\
\text { 0,665 signifikan menunjukkan bahwa hampir }\end{array}$} \\
\hline & P & 61 & $2,0(1-5)$ & 1 & \\
\hline \multirow{2}{*}{$\begin{array}{l}\text { Rugae } \\
\text { Fragment } \\
\text { er }\end{array}$} & L & 61 & $1,0(0-$ & (1,00 & \\
\hline & P & 61 & $1,0(0-4)$ & $1,16 \pm 0,879$ & \\
\hline
\end{tabular}

Tabel 1. Perbandingan Ukuran rugae pada laki-laki dan perempuan suku Minang

Tabel menunjukkan bahwa tidak terdapat perbedaan yang signifikan $(p>0,05)$ pada jumlah ukuran pola rugae palatal antara laki-laki dan perempuan suku Minang. Terdapat persamaan ukuran rugae yang mendominasi pada laki-laki dan perempuan suku Minang, yaitu rugae primer, lalu diikuti oleh rugae sekunder dan rugae fragmenter. Uji Mann-Whitney tidak menunjukkan adanya perbedaan signifikan, namun hasil analisis menunjukkan bahwa pola rugae primer pada laki-laki lebih banyak dibandingkan dengan perempuan.

\begin{tabular}{|c|c|c|c|c|c|}
\hline Bentuk & $\begin{array}{c}\text { Jenis } \\
\text { Kelamin }\end{array}$ & $\mathbf{n}$ & $\begin{array}{c}\text { Median } \\
\text { (min-maks) }\end{array}$ & Mean \pm SD & $p$ \\
\hline \multirow[t]{2}{*}{ Unifikasi } & L & 61 & $1,0(0-4)$ & $1,34 \pm 1,031$ & \multirow{2}{*}{0,72} \\
\hline & $P$ & 61 & $1,0(0-5)$ & $1,11 \pm 1,266$ & \\
\hline \multirow[t]{2}{*}{ Bergelombang } & L & 61 & $4,0(1-9)$ & $3,82 \pm 1,821$ & \multirow{2}{*}{0,806} \\
\hline & $\mathrm{P}$ & 61 & $4,0(1-8)$ & $3,84 \pm 1,635$ & \\
\hline \multirow[t]{2}{*}{ Lurus } & L & 61 & $2,0(0-6)$ & $2,18 \pm 1,420$ & \multirow{2}{*}{0,372} \\
\hline & $P$ & 61 & $2,0(0-4)$ & $1,89 \pm 1,226$ & \\
\hline \multirow[t]{2}{*}{ Kurva } & L & 61 & $2,0(0-5)$ & $1,85 \pm 1,138$ & \multirow{2}{*}{0,294} \\
\hline & $P$ & 61 & $2,0(0-6)$ & $2,11 \pm 1,253$ & \\
\hline \multirow[t]{2}{*}{ Sirkular } & $\mathrm{L}$ & 61 & $1,0(0-3)$ & $0,74 \pm 0,772$ & \multirow{2}{*}{$0,002^{*}$} \\
\hline & $\mathrm{P}$ & 61 & $0,0(0-2)$ & $0,31 \pm 0,534$ & \\
\hline
\end{tabular}

Tabel 2. Perbandingan Pola rugae pada laki-laki dan perempuan suku Minang

Berdasarkan hasil perhitungan pada tabel 2, didapatkan adanya perbedaan yang signifikan $(p<0,05)$ pada ada atau tidaknya semua sampel perempuan tidak memiliki pola sirkular. Namun pada proses pengambilan data terdapat beberapa sampel perempuan yang memiliki pola sirkular dengan jumlah yang lebih sedikit dari lakilaki serta sebagian sampel laki-laki juga tidak memiliki pola sirkular.

\section{PEMBAHASAN}

Penelitian pada etnis Igbo dan etnis Ikwerre di Nigeria menunjukkan bahwa pada kedua etnis ini ditemukan 6 jenis pola rugae palatal diantaranya bergelombang, kurva, lurus, sirkular, konvergen, dan divergen. Etnis Igbo memiliki pola bergelombang yang lebih banyak dibanding Ikwerre, sementara pola kurva mendominasi etnis Ikwerre. Etnis Igbo didominasi oleh pola bergelombang, dan Ikwerre didominasi oleh pola lurus dan kurva.

Penelitian pada suku India menunjukkan bahwa Jumlah rugae sebelah kanan pada perempuan lebih banyak dibandingkan laki-laki. Rugae sebelah kiri 
tidak terdapat perbedaan signifikan antara keduanya. Populasi ini ditemukan empat jenis pola yaitu kurva, bergelombang, lurus, sirkular. Pola kurva dan lurus lebih banyak ditemukan pada perempuan, sementara pada laki-laki didominasi oleh pola bergelombang ${ }^{5}$.

Terdapat perbedaan signifikan pada rugae palatal sebelah kiri antara penduduk keturunan Deutro Melayu dengan keturunan cina di Jawa Tengah dan perbedaan signifikan pada ukurannya ${ }^{15}$.

Laki-laki populasi suku jawa memiliki semua bentuk pola rugae palatal, namun pada perempuan tidak ditemukan adanya pola sirkular, konvergen, dan divergen. Populasi suku Jawa memiliki perbedaan jumlah bentuk pola, jumlah suatu pola pada gender tertentu. Penyebabnya mungkin karena adanya perbedaan bentuk dan ukuran rahang antara laki-laki dan perempuan, sehingga nantinya hal ini bisa dijadikan sebagai salah satu bentuk khas pola rugae palatal pada populasi Jawa ${ }^{16}$.

Penelitian ini dilakukan untuk menguji adanya perbedaan pada pola rugae palatal antara laki-laki dan perempuan suku Minang pada siswa SMKN 3 Kota Pariaman menggunakan metode pembuatan cetakan gigi rahang atas. Penggunaan cetakan gigi sebagai salah satu metode untuk menganalisis rugae palatal memiliki keuntungan yaitu analisis yang sederhana, biaya yang murah, bahan dan alat yang mudah didapat, serta mengurangi resiko kesalahan jika dilakukan pemeriksaan intraoral langsung ${ }^{4}$.

Penelitian menemukan bahwa ukuran pola rugae palatal laki-laki suku Minang didominasi oleh pola rugae yang berukuran lebih panjang dari $5 \mathrm{~mm}$. Bentuk pola rugae palatal laki-laki suku Minang didominasi oleh bentuk bergelombang dan bentuk lurus. Laki-laki suku minang memiliki semua bentuk pola rugae palatal. Hal ini memiliki kemiripan dengan laki-laki populasi Jawa yang juga merupakan bagian dari subras Deutro Melayu juga. Laki-laki populasi Jawa memiliki semua bentuk pola rugae palatal.

Pola rugae laki-laki pada populasi Arab didominasi oleh pola bergelombang. Laki-laki populasi Serbia didominasi oleh pola sirkular. Laki-laki populasi India didominasi oleh bentuk sirkular ${ }^{17}$.

Ukuran pola rugae palatal perempuan suku Minang didominasi oleh pola rugae yang berukuran lebih panjang dari $5 \mathrm{~mm}$. Bentuk pola rugae palatal perempuan suku Minang didominasi oleh bentuk bergelombang dan bentuk kurva. Perempuan suku Minang umumnya tidak memilki bentuk pola sirkular. Hal ini memilki kemiripan dengan perempuan populasi Jawa. Perempuan populasi Jawa 
tidak memiliki pola sirkular dan pola divergen ${ }^{16}$.

Jumlah rugae primer pada suku Minang lebih banyak dibandingkan dengan rugae sekunder pada kedua gender. Hal ini sesuai penelitian yang dilakukan oleh pada populasi India bahwa ukuran rugae didominasi oleh pola primer. Ukuran rugae populasi Nepal didominasi oleh pola rugae $\operatorname{primer}^{18,19}$.

Jumlah ukuran pola rugae secara keseluruhan antara laki-laki dan perempuan suku Minang pada penelitian ini tidak memiliki perbedaan yang signifikan sehingga tidak dapat digunakan untuk menentukan jenis kelamin pada identifikasi forensik. Hal ini sesuai dengan penelitian pada populasi India, jumlah ukuran pola rugae tidak menunjukkan perbedaan signifikan antara laki-laki dan perempuan. Bajracharya juga menyatakan bahwa tidak terdapat perbedaan yang signifikan pada rugae primer antara laki-laki dan perempuan populasi Nepal ${ }^{18,19}$.

Walaupun tidak terdapat perbedaan yang signifikan, laki-laki suku Minang memiliki nilai rata-rata pola primer dan pola sekunder yang lebih banyak dibandingkan perempuan suku Minang meskipun berasal dari suku yang sama. Hal ini kemungkinan disebabkan karena perbedaan lebar palatum antara kedua gender, sehingga gender yang memiliki palatum lebih lebar memiliki jumlah rugae primer dan rugae sekunder yang lebih banyak $^{20}$.

Ukuran rugae palatal dipengaruhi oleh pertumbuhan dan ekstraksi gigi Variasi pola rugae pada masing-masing populasi kemungkinan umumnya dipengaruhi oleh faktor genetik dan dan sebagian kecil faktor lingkungan ${ }^{20}$.

Pola rugae suku Minang didominasi oleh pola bergelombang. Keturunan Deutro Melayu, pola rugae yang paling dominan adalah pola bergelombang ${ }^{15}, 21$. Hal ini dikarenakan pembentukan pola bergelombang pada masa embrional sangat dominan. Perbedaan pola rugae tiap populasi juga dibuktikan dengan penelitian yang menyatakan bahwa suku Aborigin didominasi oleh pola bergelombang dan kurva $^{14}$. Ras caucasoid didominasi oleh pola lurus ${ }^{13}$. Ras Serbia didominasi oleh pola bergelombang dan pola kurva.

Perbedaan bentuk pola rugae yang mendominasi pada suku Minang dengan ras atau populasi lain merupakan bagian dari ciri khas populasi tersebut sehingga menimbulkan keberagaman bentuk pola dominan $^{16}$. Selain itu kemungkinan hal ini disebabkan perbedaan pola makan dan genetik yang berbeda ${ }^{21}$. Perbedaan bentuk pola dipengaruhi oleh ras dan lokasi geografi $^{13}$. perbedaan gaya hidup salah 
satunya adalah makanan yang beberapa penelitian. Penelitian dikonsumsi ${ }^{15}$. menunjukkan bahwa tidak terlihat

Suku Minang memiliki semua jenis perbedaan yang signifikan antara laki-laki pola rugae palatal berdasarkan klasifikasi dan perempuan populasi Sudan sehingga Thomas dan Kotze. Bentuk pola rugae analisis pola rugae palatal tidak dapat palatal antara laki-laki dan perempuan suku digunakan untuk populasi tersebut. Kapali Minang menunjukkan perbedaan yang tidak menemukan adanya perbedaan antara signifikan pada pola sirkular. Perempuan suku Minang tidak memiliki pola sirkular. Hasil ini menunjukkan bahwa ada perbedaan pola rugae palatal antara lakilaki dan perempuan yang dijadikan sampel. Hal ini sesuai dengan penelitian Nurdiansyach terhadap populasi Jawa yang juga merupakan subras Deutro Melayu. Perempuan populasi Jawa tidak memiliki pola sirkular dan pola divergen ${ }^{16}$.

Pola rugae pada populasi Bhopal di India menunjukkan perbedaan antara lakilaki dan perempuan. Pola bergelombang dan pola kurva lebih banyak pada perempuan dibandingkan pada laki-laki dan pola kurva $^{12}$.

Populasi arab saudi menunjukkan tidak terjadi perbedaan signifikan jumlah rugae antara laki-laki dan perempuan, namun terdapat perbedaan signifikan pada beberapa bentuk. Pola konvergen lebih banyak dijumpai pada perempuan, sementara pola sirkular lebih banyak pada laki-laki ${ }^{13}$.

Perbedaan laki-laki dan perempuan laki-laki dan perempuan Aborigin ${ }^{20}$.

Perbedaan ada atau tidak adanya suatu pola pada rahang atas laki-laki dan perempuan, menunjukkan ciri khas rugae palatal dari tiap populasi ${ }^{19}$. Perbedaan bentuk pola rugae palatal antara laki-laki dan perempuan pada ras yang sama kemungkinan disebabkan oleh perbedaan ukuran dan bentuk rahang antara laki-laki dan perempuan ${ }^{16}$.

Selain itu jumlah rugae perempuan yang lebih sedikit dibanding laki-laki kemungkinan disebabkan karena adanya evolusi regresif yang lebih jelas terjadi pada perempuan dibandingkan laki-laki pada masa embrional sehingga mempengaruhi pola awal rugae yang bersifat tetap dari awal masa kelahiran sampai terjadinya degenerasi mukosa oral setelah kematian. Perbedaan pola rugae yang dominan pada laki-laki dan perempuan suku Minang merupakan bagian dari sexual dimorphism sehingga rugae palatal dapat dijadikan salah satu acuan untuk identifikasi jenis kelamin $^{20}$.

suku Minang berbanding terbalik dengan 
Meskipun penelitian ini hanya menggunakan 122 sampel, namun hasil penelitian ini telah menunjukkan bahwa terdapat perbedaan antara bentuk pola rugae laki-laki dan perempuan suku Minang. Hal ini merupakan sumbangan ilmiah bagi dunia penelitian Odontologi Forensik, khususnya sebagai acuan identifikasi jenis kelamin.

\section{KESIMPULAN}

Berdasarkan penelitian yang telah dilakukan terhadap 122 sampel, maka diperoleh kesimpulan sebagai berikut :

1. Ukuran pola rugae laki-laki suku Minang didominasi oleh rugae primer, sedangkan bentuk pola rugae didominasi oleh pola bergelombang, lalu diikuti pola lurus, pola kurva, pola unifikasi dan pola sirkular.

2. Ukuran pola rugae perempuan suku Minang didominasi oleh rugae primer, sedangkan bentuk pola rugae palatal didominasi oleh bentuk pola bergelombang, lalu diikuti pola kurva, pola lurus, pola unifikasi.

3. Tidak terdapat perbedaan ukuran pola rugae palatal antara laki-laki dan perempuan suku Minang pada, namun terdapat perbedaan bentuk pola rugae palatal antara laki-laki dan perempuan suku Minang. Perempuan suku Minang tidak memiliki pola sirkular pada rugae palatal.
4. Walaupun penelitian ini tidak memperlihatkan perbedaan signifikan jumlah rugae, namun analisis statistik memperlihatkan terdapat perbedaan signifikan pada bentuk pola rugae. Pola rugae palatal dapat dijadikan metode alternatif untuk membedaan perempuan dan laki-laki suku Minang.

\section{SARAN}

Berdasarkan hasil penelitian, pembahasan dan kesimpulan di atas, maka disarankan melakukan penelitian lanjutan dengan menggunakan jumlah sampel yang lebih banyak, menggunakan metode identifikasi rugae palatal yang berbeda untuk memperkuat hasil penelitian, serta melihat pengaruh pertambahan usia terhadap ukuran dan bentuk pola rugae palatal dengan sampel yang sama.

\section{KEPUSTAKAAN}

1. Cyrilh, Wecht. dkk . (2007). Forensic investigation and management of mass disaster. - : Lawyers \& Judges Publishing Company.

2. Venegas, Valeria Hermosilla, Jaime San Pedro Valenzuela, Mario Cantín López, Iván Claudio Suazo Galdames. (2009). Palatal rugae: systematic analysis of its shape and dimensions for use in human identification. International Journal of Morphology, 27 (3), 19-25.

3. Saxena, Susmita, Pretti Sharma, Nitin Gupta. (2010). Experimental studies of forensic odontology to aid identification process. Forensic Dental Sci 2 (2), 69-76.

4. Chairani Shanty, Elza I Auerkari. (2008). Pemanfaatan Ruga Palatal 
Untuk Identifikasi Forensik. Indonesian Journal of Dentistry. Vol 15 (3), 261269.

5. Manjunath, S, Shankar M Bakkannavar, Pradeep Kumar G,Vrinda J Bhat, Nayana Prabhu, Asha Kamath, Raghavendra Babu Y P. (2012). Palatal rugae patterns among the Indians at Manipal, India. Journal of Pharmaceutical and Biomedical Science Vol 20.

6. Swetha, S. 2015. Palatal rugae patterns in Varied Adult Indian Population of Males and Females. Journal of Pharmaceutical Sciences and Research Vol 7 (9), 736-739.

7. Muthusubramanian, M, K.S.Limson, R.Julian. (2005). Analysis Of Rugae Palatal In Burn Victims And Cadavers To Simulate Rugae Identification In Case of Incineration And Decomposition. The Journal Of Forensic Odontology-Stomatology, Vol.23 (1), 26-29.

8. Elsy. (2015). Asal Usul Sumatera Barat. Retrieved from www.news.padek.co/detail.php?news= $\underline{27965}$

9. Kapali, Sunita, Grant Townsend, Lindsay Richards, Tracey Parish. (1997). Palatal rugae pattern in Australian Aborigines and Caucasian. Australian Dental Journal, 42 (2), 129133

10. Shetty deeksha kiran. Sheetal Mali, Hegde Deepak Divakar . (2015). Palatal rugae patterns as bioindicators for forensic identification in Kodava and Tibetan populations of India. Journal of International oral health, 7(2), 57-59.

11. Sabarigirinathan, C, K. Vinayagavel, A. Meenakshi, C. Selvamani, G. Sriramaprabu, S. Sivasakthikumar, R.Appadurai, K. Usha, S. Srividhya. (2015). Palatal rugae ini forensic odontology. IOSR Joural of Dental and Medical Sciences, vol 14 (10), 83-87.

12. Jain, Shilpa, Arpit Jain. (2015). Rugoscopy as an adjunct to sex differentiation in forensic odontology. Journal of applied dental and medical sciences, vol 1(1), 1-6.
13. Ahamed, Nabeel, Victor Samuel, Mahesh R. (2015). Uniqueness of palatal rugae in forensic science. International Journal of Pharma and Bio Sciences, 6 (1), 475-479.

14. Bhullar, Amandeep, Raman Preet Kaur, Mamta Sharat Kamat. (2011). Palatal rugea - an aid in clinical dentistry. Journal Forensic Research, Vol 2 (3).

15. Anggraini, Eva Tri Wahyu. (2013). Perbedaan Pola Rugae Palatal pada Penduduk Keturunan Deutro Melayu dengan Keturunan Cina di Jawa Tengah. Jurnal Media Medika Muda.

16. Nurdiansyach, Iman, Mieke Sylvia M.A.R, Susy Kristiani. 2013. Pola palatal rugae pada populasi jawa sebagai sarana identifikasi forensik (studi kasus pada mahasiswa fakultas kedokteran gigi universitas airlangga).

17. Saraf, A, S Bedia, A. Indurkar, S. Degwekar. R. Bhowate. (2011). Rugae Pattern as an adjunct to sex differentiation in forensic identification. Journal Forensic Odontostomatol, 29 (1), 14-19.

18. Bajracharya, Dipshikha, Anisha Vaidya, Sunaina Thapa, Sujita Shresths. (2013). Palatal Rugae Pattern in Nepalese Subjects. Orthodontic Journal of Nepal, Vol 3 (2), 36-39.

19. Subramanian, Prathusha, Nithya Jagannathan. (2015). Palatal rugoscopy as a method of sex determination in forensic science. Asian Journal of Pharmaceutical and Clinical Research, vol 8 (2), 136-138.

20. Ahmed, Altayeb Abdalla, Awrad Hamid. (2014). Morphological study of palatal rugae in a sudanese population. International Journal of Dentistry.

21. Aditana, Donny, Oedijani Santoso. (2015). Perbedaan pola dan ukuran ruge palatal ras Deutro melayu dengan ras Australoid. Media Medika Muda, vol 4 (1). 